\title{
microRNAs 424 and 503 are mediators of the anti-proliferative and anti-invasive action of the thyroid hormone receptor beta
}

\section{Lidia Ruiz-Llorente, Soraya Ardila-González, Luisa F Fanjul, Olaia Martínez- Iglesias and Ana Aranda}

Instituto de Investigaciones Biomédicas, Consejo Superior de Investigaciones Científicas and Universidad Autónoma de Madrid, Arturo Duperier 4, 28029 Madrid, Spain

Correspondence:

Ana Aranda, e-mail: aaranda@iib.uam.es

Keywords: thyroid hormone receptor, microRNA-424, microRNA-503, proliferation, invasion, hepatocarcinoma and breast cancer cells

Received: November 05, $2013 \quad$ Accepted: March 27, $2014 \quad$ Published: April 02, 2014

Abbreviations: HAT, histone acetyltransferase; T3, triiodothyronine; TRb, thyroid hormone receptor beta; SK-TRb, SK-hepl cells stably expressing the TRb isoform, MDA-TRb, MDA-MB-468 cells stably expressing TRb.

\section{ABSTRACT}

The thyroid hormone receptors (TRs) mediate tumor suppressive effects in hepatocarcinoma and breast cancer cells. Here we show that incubation of hepatocarcinoma SK-hep1 cells expressing TRb with the thyroid hormone T3 induces transcription of the polycistronic message coding for microRNAs 424 and 503. TRb binds to the promoter region of these miRNAs and T3 induces an exchange of corepressors and coactivators inducing histone acetylation and transcriptional stimulation. We have validated cell cycle components as targets of these miRNAs. Overexpression of miR-424 mimicked the repressive effect of T3 on cell proliferation, growth in suspension, migration and invasion. Knockdown of miR-424 or miR-503 reduced the inhibitory effect of the hormone. T3 increased miR-424 and miR-503 in breast cancer cells expressing TRb, and this induction is also involved in the antiinvasive effects of the hormone. Furthermore, miR-424 or miR-503 depletion enhanced extravasation to the lungs of hepatocarcinoma cells injected in the tail vein of mice. The levels of these miRNAs were reduced in xenograft tumors formed in hypothyroid nude mice that are more invasive. Therefore, miR-424 or miR-503 mediate antiproliferative and anti-invasive actions of TRb both in cultured cells and in vivo.

\section{INTRODUCTION}

The actions of the thyroid hormone triiodothyronine (T3) are mediated by binding to nuclear receptors (TR alpha and beta), which act as ligand-dependent transcription factors by association to thyroid hormone response elements (TREs) in target genes [1]. TRs play an important role in cell proliferation and cancer $[2,3]$. In hepatocarcinoma cells expressing $\mathrm{TRb}, \mathrm{T} 3$ reduces proliferation [4], the responses to the ras oncogene [5], and the expression of pituitary tumor-transforming 1 , a critical mitotic checkpoint protein [6]. Thyroid hormone treatment induces regression of carcinogen-induced hepatic nodules, reducing the incidence of hepatocarcinoma and lung metastasis in rodents $[7,8]$. Furthermore, decreased TR levels and somatic mutations in TR genes have been found in more than $70 \%$ of human hepatocarcinomas, and most of these mutants act as dominant-negative inhibitors of TR activity [9-12]. Inactivation of TRb by promoter methylation, mutations, altered expression and anomalous subcellular localization of TRs has also been described in breast tumors [13-15]. These observations suggests that native TRs could act as tumor suppressors, and indeed expression of TRb in hepatocarcinoma and breast cancer cells retards tumor growth and strongly reduces invasion, extravasation and metastasis formation in nude mice $[16,17]$

MicroRNAs (miRNAs) are single-stranded RNA molecules of 20-23 nucleotides length that post-transcriptionally control gene expression [18]. miRNAs bind to 3' untranslated regions (3' UTRs) of mRNA transcripts and promote mRNA degradation or translational inhibition [19-22]. Many miRNAs have oncogenic or tumor suppressive actions [23-25]. Among them, the miR-16 family regulates cell proliferation 
[26-28] and miR-503, a miR-16 family member, might be a master regulator of the cell cycle [29]. miR-503 is an intragenic miRNA clustered with miR-424, other miR-16 family member, and both are produced as a polycistronic message [30]. Various targets of these miRNAs regulate cell division, the cell cycle, mitosis or angiogenesis [31-37]. In addition, miR-424 and miR-503 are involved in cancer cell migration and invasion [38, 39], and are reduced in human hepatocarcinoma tumors [40].

In this work we show that miR-424 and miR-503 are transcriptionally induced by T3 in hepatocarcinoma and breast cancer cells expressing TRb, and demonstrate that this induction appears to play an important role in the antiproliferative and anti-invasive actions of the hormone both in cultured cells and in vivo.

\section{RESULTS}

\section{T3 induces transcriptional activation of miR-424 and miR-503}

In miRNA microarrays we found that miR-424 and miR-503 levels were higher (2.32- and 2.99-fold, respectively) in T3-treated SK-hep1 cells expressing TRb (SK- TRb) than in untreated cells. The expression levels of both miRNAs measured by quantitative RT-PCR were increased upon $\mathrm{T} 3$ treatment, validating the microarrays results (Figure 1A). This increase was not found in parental cells that do not express TRb (Suppl. Figure 1), indicating that the effect of $\mathrm{T} 3$ requires binding to the receptor. Expression of miR-424 and miR-503 was, however, undetectable in parental and TRb-expressing HepG2 cells both in the absence and presence of T3
(Suppl. Figure 2A,B). In addition, T3 did not increase the levels of these miRNAs in non-transformed THLE-2 hepatocytes. However, the hormone induced miRNA expression in HH4 hepatocytes, and this induction was stronger after transduction with a retroviral vector encoding $\mathrm{TRb}$ (HH4-TRb cells) (Suppl. Figure 2B). These cells express the receptor at similar levels as those found in SK-TRb or HepG2-TRb cells (Suppl. Figure 2B). Therefore, induction of miR-424 and miR-503 by T3 is not restricted to hepatocarcinoma cells.

T3 increased the levels of pri-miRNA-424 and primiRNA-503 in SK- TRb cells (Figure 1B), suggesting that the hormone induces transcription of the miRNAs precursor. To analyze the presence DNA elements that could mediate T3-dependent transcription, we constructed luciferase reporter plasmids containing different fragments of the miRNAs $5^{\prime}$-flanking region (Figure 1C). Activity of the $-923 /-34$ region with respect to the transcription start site of miR-424 was increased by T3. However, no change was observed when cells were transfected with the luciferase plasmid alone or with other fragments, indicating that this region contains the elements responsible for stimulation of miR-424/503 by T3.

ChIP assays were carried out with the region containing the putative response elements (Figure 1D). $\mathrm{TRb}$ bound constitutively to two overlapping fragments of the proximal promoter region, whereas no receptor recruitment to an irrelevant upstream region (-3723-/3911) was observed (Figure 1E). Furthermore, T3 caused dissociation of the corepressor NCoR and recruitment of p160 coactivators and CBP to the promoter. Consequently, enrichment on acetylated $\mathrm{H} 4$ histone was also detected (Figure 1F).
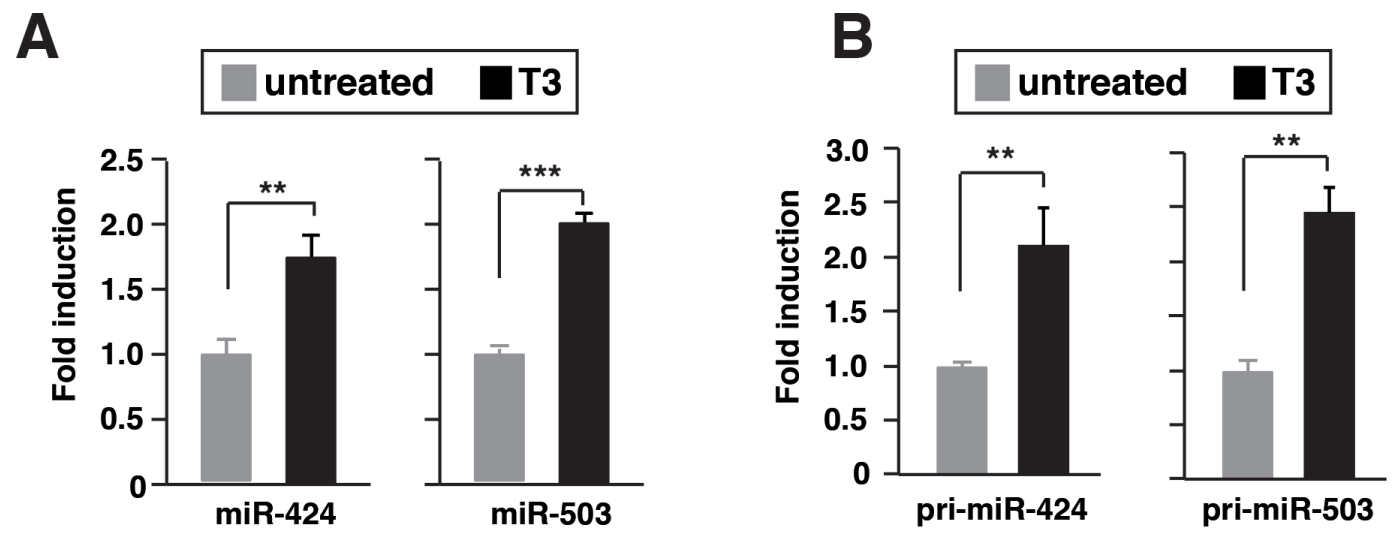

Figure 1: T3 induces transcription of miR424 and miR503 in hepatocarcinoma cells. (A) miR-424 and -503 levels after $48 \mathrm{~h}$ of treatment with 5nM T3 in TRb-expressing SK-hep1 cells. Fold change of these microRNAs are expressed relative to control untreated cells. (B) pri-miRNA levels measured under the same conditions.

(Continued) 

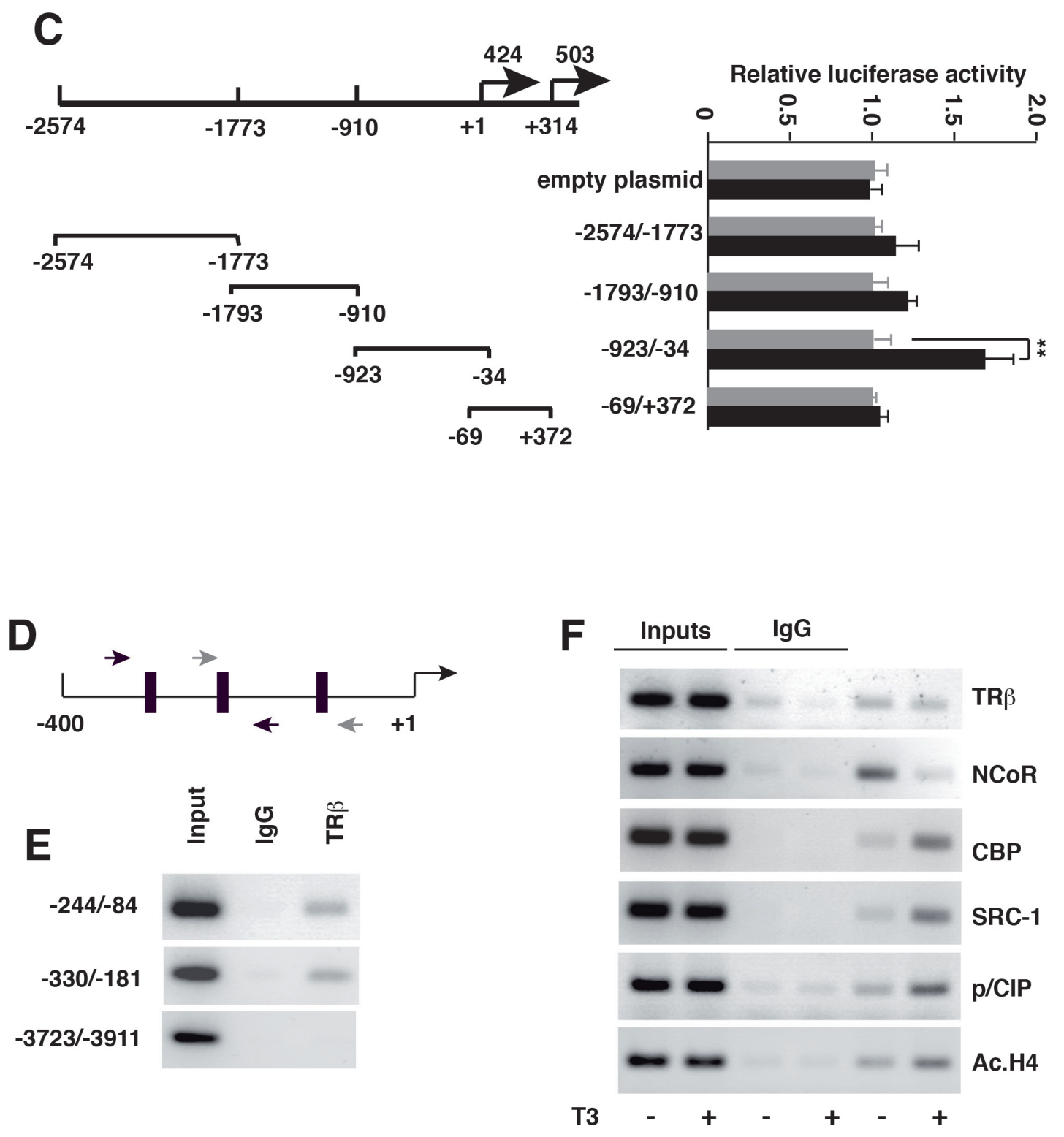

Figure 1: (C) Schematic diagram of the 5 '-flanking region of miRNA424/503, and the fragments used in transient transfection studies. Cells were transfected with the empty luciferase plasmid or with the plasmids containing the indicated regions of the miRNA-424/-503 promoter. Luciferase activity was determined in control cells and in cells treated with T3 for $48 \mathrm{~h}$. (D) Schematic representation of the miRNA-424/-503 proximal promoter depicting the position of the putative receptor binding sites (black boxes) and the primers used in chromatin immunoprecipitation (ChIP) assays (arrows). (E) ChIP assays with IgG and TRb antibodies and the indicated fragments of the miRNA-424/-503 promoter. (F) Binding of TRB, the corepressor NCoR, the coactivators CBP, SRC-1 and p/CIP and acetylated histone H4 to the miRNA-424/-503 promoter region -244/-84, determined by ChIP assays after $1 \mathrm{~h}$ of incubation with T3.

\section{T3 down-regulates miR-424 and miR-505 targets}

miR-424 and miR-503 are predicted to target many mRNAs (microRNA and TargetScan), some of them already validated $[31,37,41]$. In SK-TRb cells, T3 downregulated mRNA levels of Ccnd2, Cdk6, Cdc25, E2f3, c-Myb, Wee1 and Chk1 involved in cell proliferation and cancer (Figure 2A). Furthermore, the levels of these proteins, assessed by western blot, were reduced in T3-treated cells (Figure 2B). This is compatible with the hormone-dependent induction of miRNAs 424 and 503.
The 3'-UTRs of the tested mRNAs have sequences that could anneal to the seed sequences of miR-424 and 503 (Suppl. Figure 3). To validate the predicted miRNA/ mRNA interactions, we used luciferase vectors containing the 3'-UTR of c-Myb, Cdc25A, Wee1 and Chk1. T3 did not affect the activity of the plasmid without UTR sequences, but significantly inhibited the activity of the UTR-containing constructs (Figure 2C). Therefore, T3 appears to represses target mRNA stability as a consequence of the increased levels of miR-424/503. 

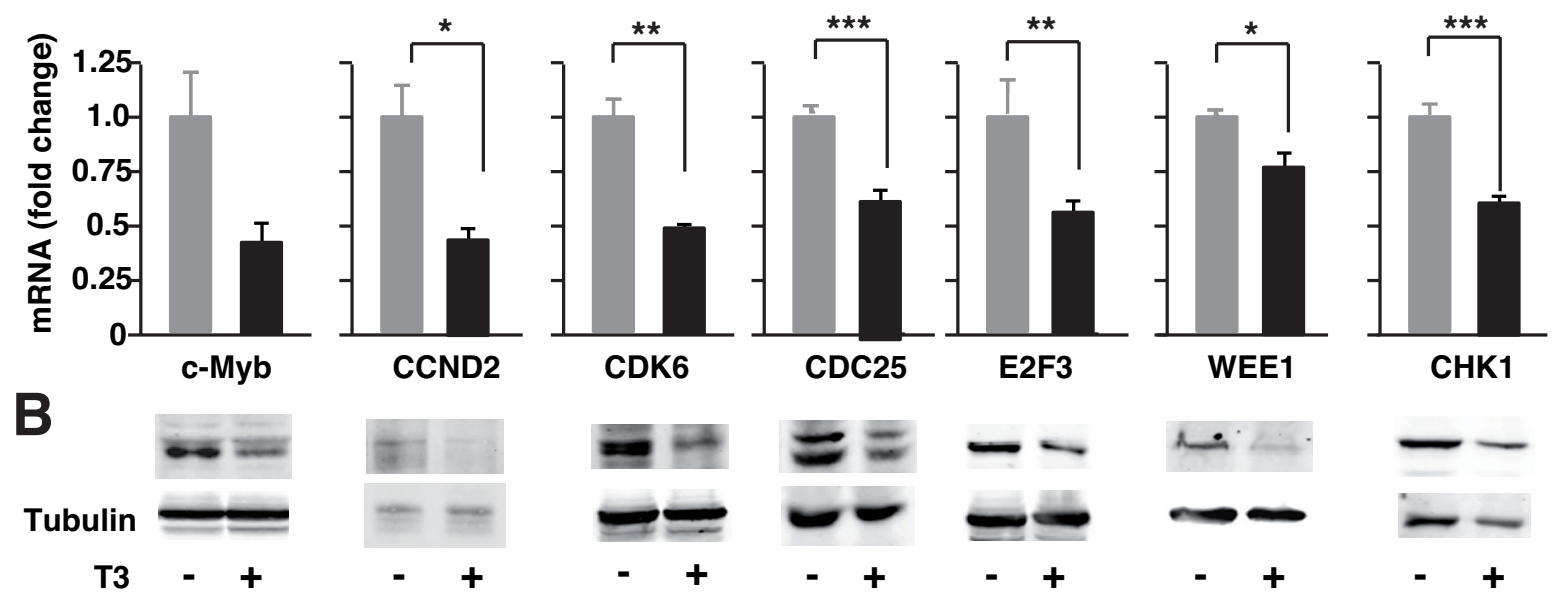

C

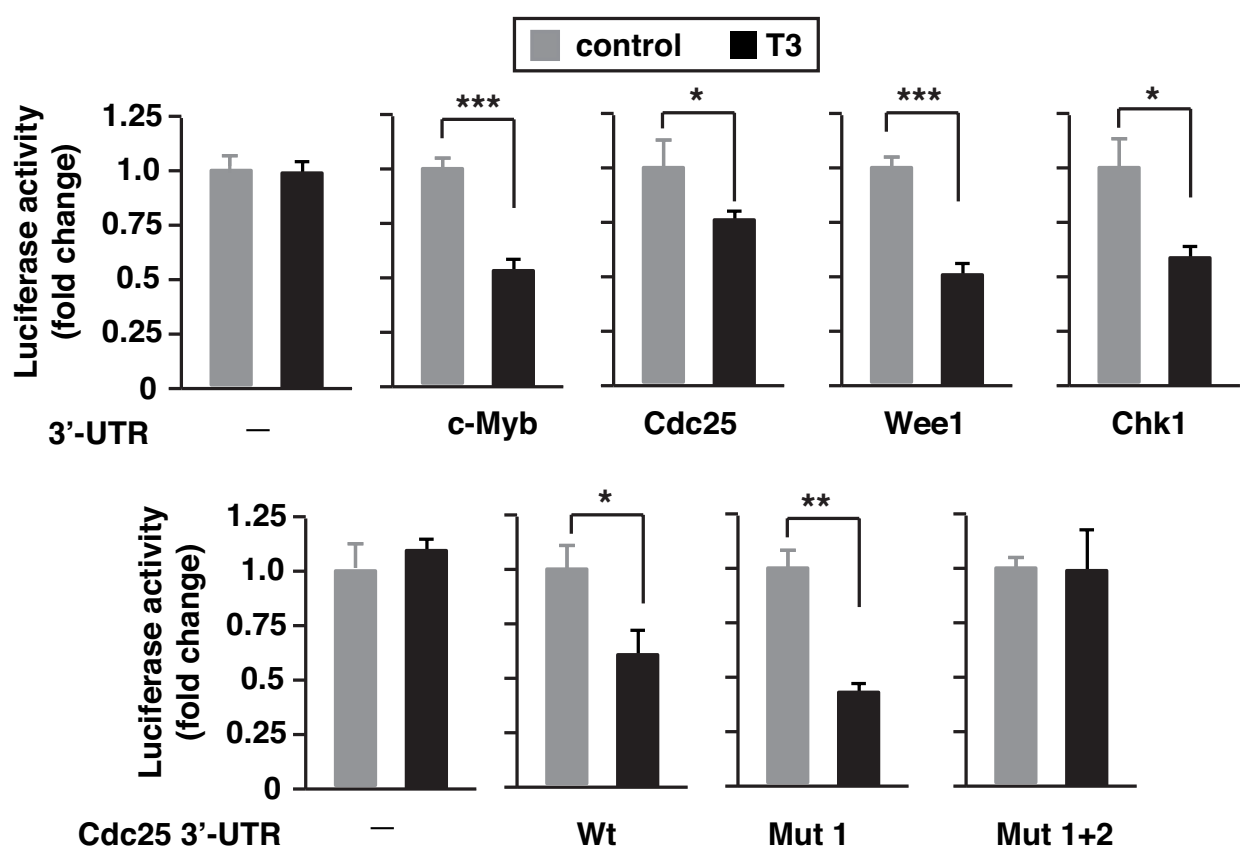

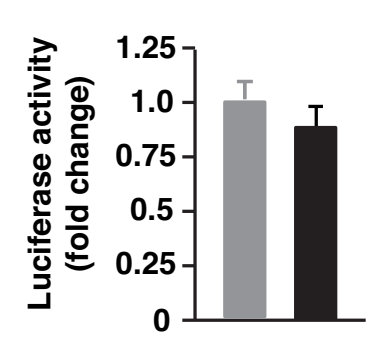

c-Myb 3'-UTR

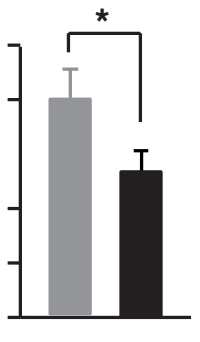

Wt



Mut 3

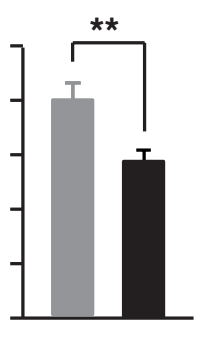

Mut 4

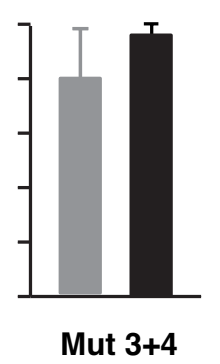

Mut 3+4

Figure 2: T3 down-regulates expression of miRNA424/503 targets. (A) mRNA levels for the indicated putative targets of miRNAs 424 and 503 were measured by quantitative PCR in SK-TRb cells treated without and with T3 for 48 h. Fold change of these mRNAs, normalized to RPL19 mRNA, are expressed relative to the values obtained in control untreated cells. (B) Western blot analysis of the same targets. Tubulin was used as a loading control. (C) Luciferase reporters fused to the c-Myb, Cdc25, Wee1 and Chek1 3,-UTRs, as well as an empty plasmid, were transfected into SK-TRb cells. A mutant construct of the proximal binding site in the Cdc25 3'-UTR is designated Mut1, the mutation in the distal binding site Mut2, and the mutation of both binding sites Mut 1+2. Mut 3 indicates mutation of the distal binding site in the c-Myb-3'-UTR, Mut4 of the proximal site and Mut $3+4$ of both sites. Luciferase activity was measured after $36 \mathrm{~h}$ incubation in the presence and absence of T3. 
Previously described mutants of the putative miR424/503 binding sites in the Cdc25 and c-Myb UTRs were used to analyze induction by T3. Cdc25 3'-UTR contains two binding sites for these miRNAs [41]. Mutation of the first site did not affect inhibition by T3. However, mutation of both sequences abrogated the repression by the hormone (Figure 2C). This shows that the reported binding sites for miR-424/503 are relevant for the effect of T3. The c-Myb UTR also contains two putative sites for these miRNAs. Mutation of the distal site alone or in combination with the proximal site abolished responsiveness to T3 (Figure 2C), in agreement with the finding that this binding site mediates the effect of miR-424 [42].
To further test the functional relevance of miR424 and miR-503 induction by T3, we conducted experiments of gain and loss of function of the miRNAs and evaluated the expression of the different targets by western blotting. Over-expression of miR-424 (Figure 3A) mimicked the effect of T3, decreasing their levels (Figure 3B). Furthermore, the reduction caused by T3 and miR-424 was not additive, indicating a common mechanism of action. On the other hand, transfection with miRNA inhibitors, which caused a strong reduction of miR-424 or miR-503 levels (Figure 3C), reversed the inhibitory effect of $\mathrm{T} 3$ on CHK1, WEE1, CDC25, c-MYB or E2EF, while CDK6 or CCND2 levels remained low (Figure 3D).
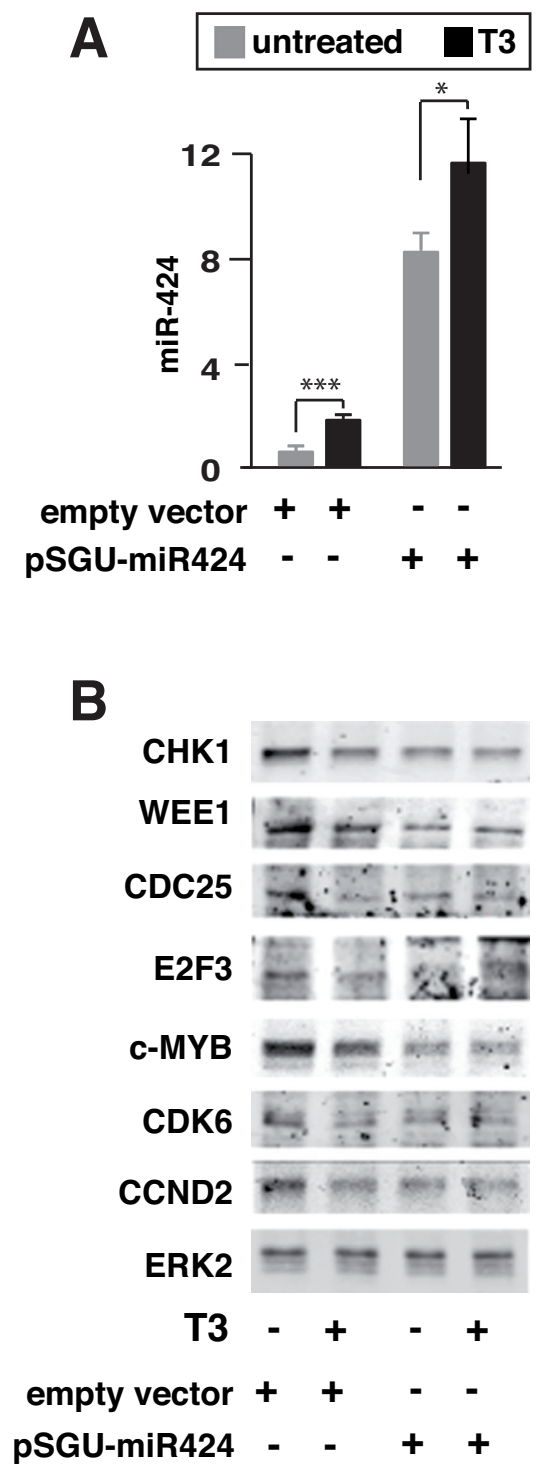
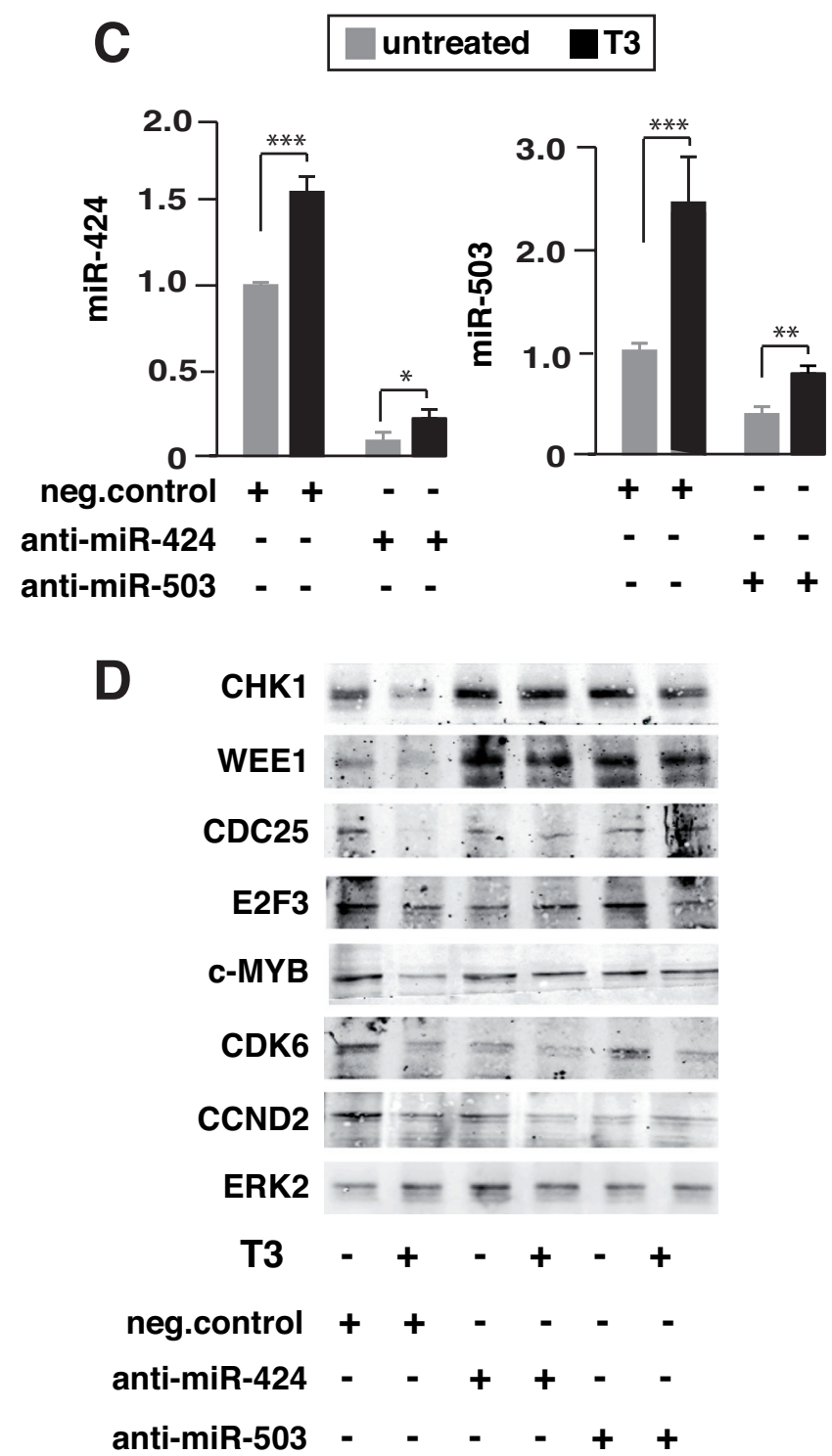

Figure 3: Influence of miR-424 expression and miR-424 and miR-503 depletion on the effect of T3 on target proteins. (A) miR-424 levels in untreated and T3-treated cells transfected $36 \mathrm{~h}$ before with an expression vector for miR-424 (pSGU-miR424) or the corresponding empty vector. (B) The levels of CHK1, WEE1, CDC25, E2F3, c-MYB, CDK6 and CCND2 were measured by western blot. ERK2 levels were used as a loading control. (C) SK-TRb cells were transfected with anti-miRNAs for miR-424 or miR-503, or with a negative control, and the levels of the corresponding miRNAs were determined in untreated and T3-treated cells $36 \mathrm{~h}$ after transfection. (D) Levels of the indicated proteins were analyzed by western blot under the same conditions. 


\section{miR424/503 depletion antagonizes the anti-} proliferative and anti-invasive actions of $\mathrm{T} 3$

Since miR-424 and miR-503 down-regulate proteins with an important role in cell proliferation, we analyzed their effect on the cell cycle of SK-TRb cells. Transfection of miR-424 increased the percentage of cells arrested in G1, causing a concomitant reduction in the number of cells in S-phase and a small increase of sub-G1 cells. Incubation with T3 did not induce cell death, but caused G1 increase and reduction of S-phase, although less marked than that caused by miR-424 overexpression. In addition, the hormone had little effect in cells overexpressing the miRNA (Figure 4A). Depletion of miR-424 or miR-503 strongly inhibited the effects of T3, and combined knockdown of both miRNAs abolished T3-dependent increase in G1 and reduction of S-phase. This indicates the crucial role of miR-424/503 induction for this hormonal effect (Figure 4B).

$\mathrm{TRb}$ expression prevents the ability of SK-hep1 cells to grow in the absence of a solid substrate [17]. Therefore, we next examined the effect of miR-424 and miR-503 on growth of SK-TRb cells in suspension under rocking conditions. miR-424 overexpression mimicked the effect of T3 inhibiting growth in suspension, while depletion of either miR-424 or miR-503 reversed T3dependent inhibition (Figure 4C). Thus, miR-424 and miR-503 induction is also involved in this action of T3

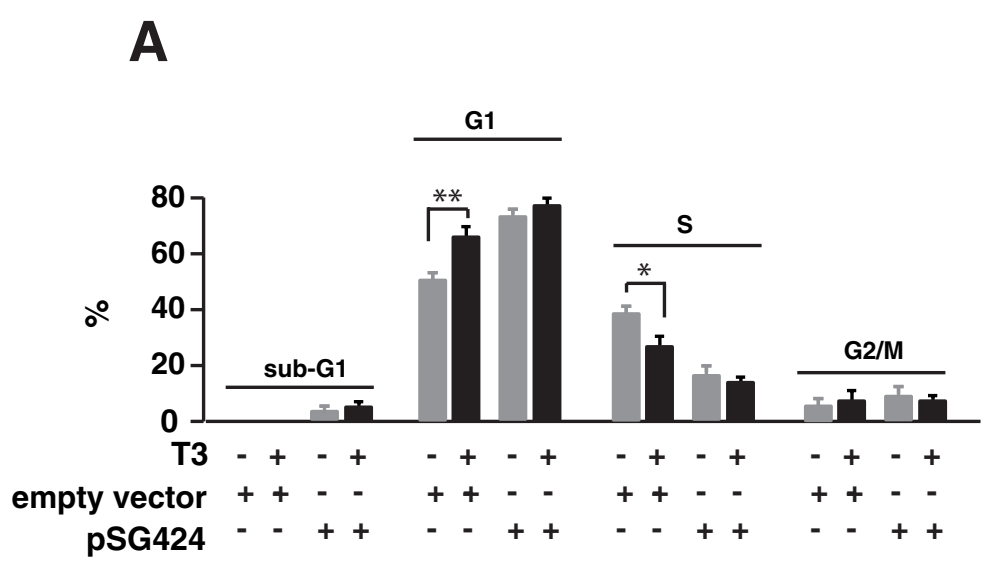

B

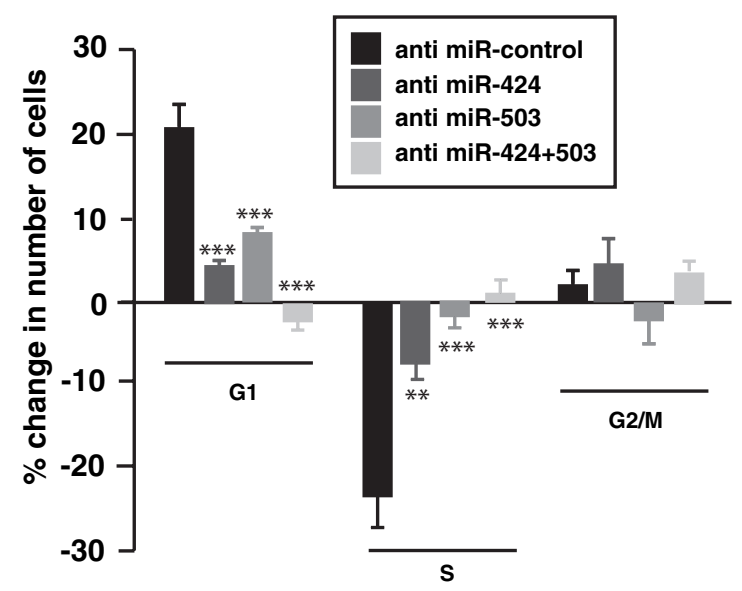

C

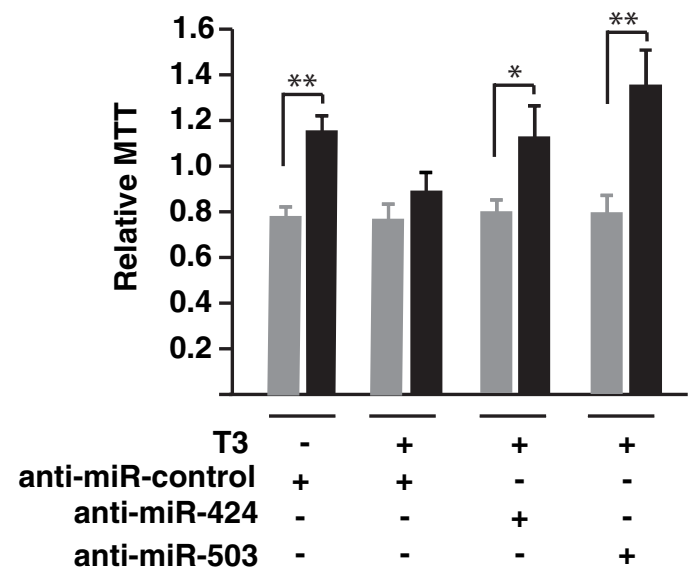

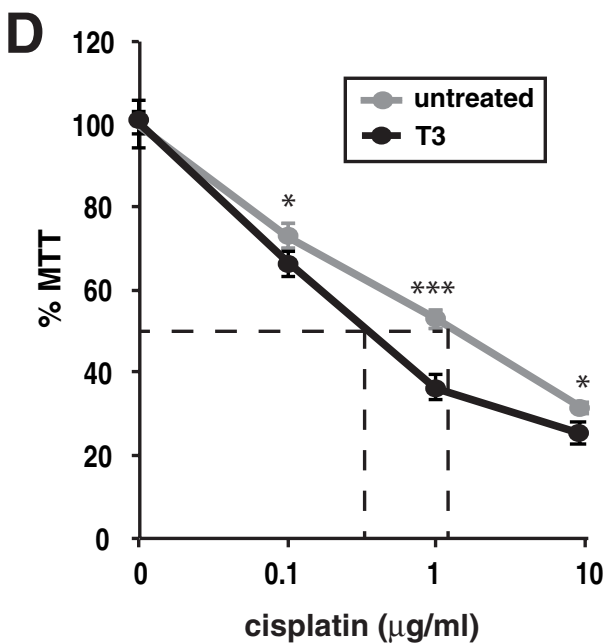

Figure 4: Inhibition of miR-424 and -503 reverses the effect of T3 on SK-TRb cell proliferation. (A) Cell cycle analysis in cells transfected with pSGU-miR424 or an empty vector. DNA contents were measured after $48 \mathrm{~h}$ of treatment with and without T3. The results are shown as the \% of cells in sub-G1, G1, S and G2/M phases. (B) Changes in the cell cycle after transfection with the negative control RNA, anti miR-424, anti miR-503 or both. The percentage of change in T3 versus untreated cells for each condition was plotted. (C) Cells were transfected with the indicated anti-miRNAs and after $24 \mathrm{~h}$ were detached from the plates and grown under rocking conditions during an additional $24 \mathrm{~h}$ period in the presence or absence of T3. Cells were then plated and MTT was assayed. Results were expressed relative to MTT values obtained in cells inoculated in parallel without agitation. (D) MTT values in cells treated with or without T3 for 72 $\mathrm{h}$ and with the indicated concentrations of cisplatin for an additional $48 \mathrm{~h}$ period. 
in SK-TRb cells. Transfection of miR-424 also reduced growth in suspension of HepG2-TRb cells that do not express miR-424 or miR-503 (Suppl. Figure 4A). In contrast, in these cells T3 did not reduce growth and, as expected, the miRNA inhibitors were ineffective (Suppl. Figure 4B).

Increased expression of Wee1 and Chk1 secondary to reduced miR-424 and other family members has been associated with resistance to cisplatin [36]. In agreement with this finding, T3 caused a moderate but statistically significant reduction of SK-TRb cell survival in response to the drug, with the EC50 decreasing from $1.6 \mu \mathrm{g} / \mathrm{ml}$ to $0.8 \mu \mathrm{g} / \mathrm{ml}$ (Figure 4D).

We next studied whether T3-induced miRNA increase could also affect cellular migration. T3 treatment or transfection with pSGU-miR424 retarded SK-TRb cell migration in wound assays (Figure 5A). Conversely, miR424 or miR-503 depletion increased wound closure and, when used in combination, reversed the inhibitory effect of T3 (Figure 5B). Therefore, induction of miRNAs 424 and 503 appears to mediate the inhibitory effect of T3 on hepatocarcinoma cell migration.

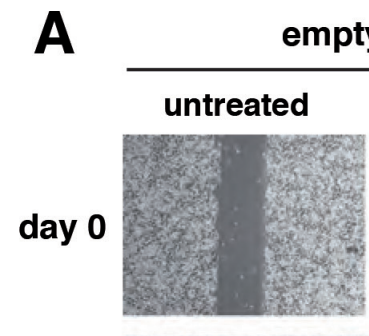

day 3
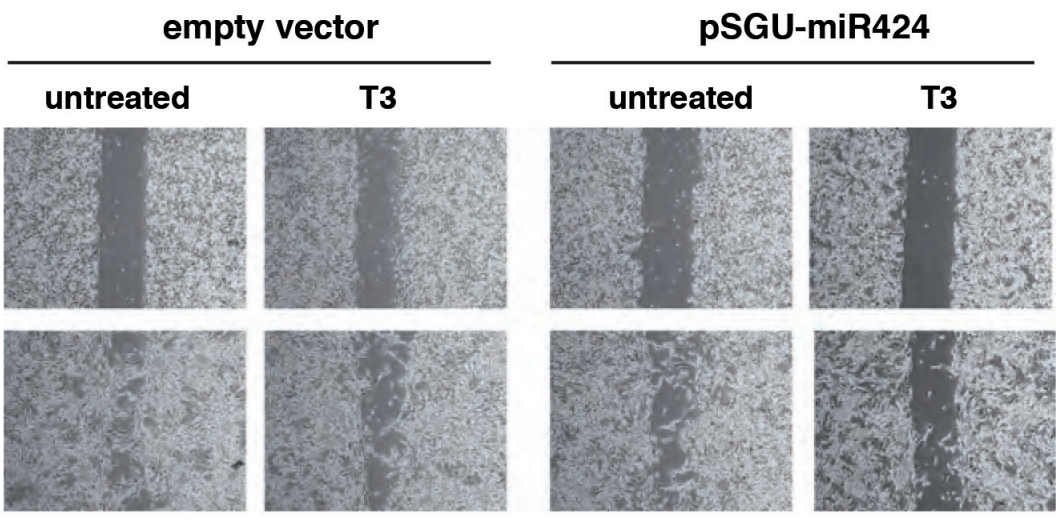

B

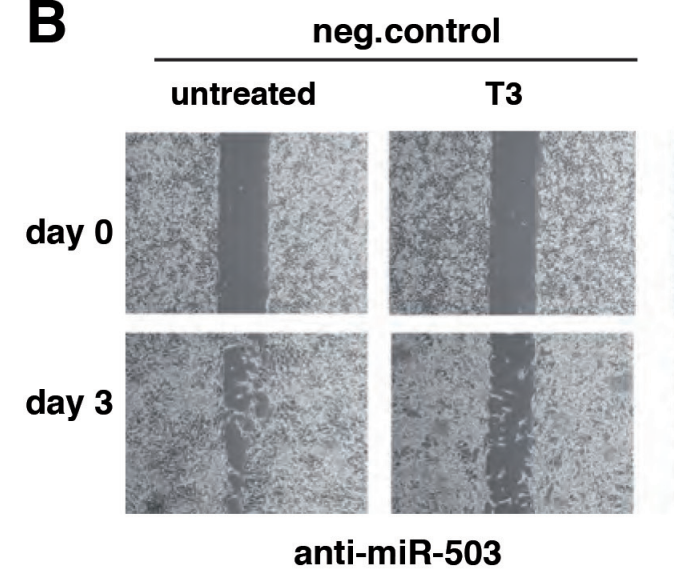

neg.control

anti-miR-424

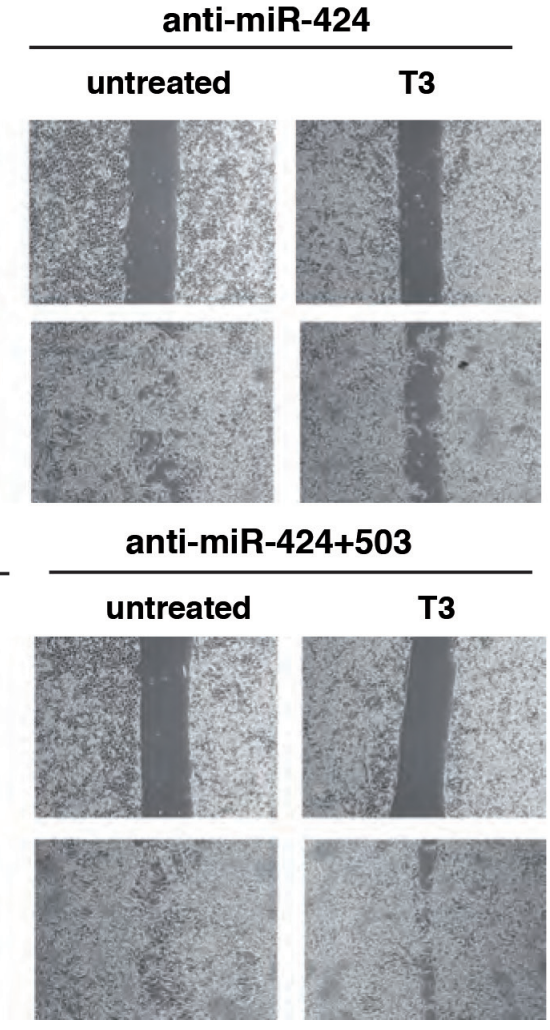

Figure 5: miR-424 and $\mathbf{- 5 0 3}$ are involved in the inhibitory effect of T3 on hepatocarcinoma cell migration. (A) Cells transfected with pSGU-miR424 or the empty vector were treated with mitomycin C to block proliferation and wound healing was followed for 3 days in the presence and absence of T3. Photographs were taken at time 0 and at day 3. Representative images are shown. (B) Similar experiment performed in cells transfected with a control anti-miRNA, or anti-miR-424 and anti-miR-503 alone or in combination. 
Our next objective was to investigate the possible role of these miRNAs on the reduced invasive capacity shown by T3-treated SK-TRb cells [17]. Figure 6A shows that over-expression of miR-424 again mimicked the effect of T3, reducing cellular invasion through matrigel. Furthermore, depletion of miR-424, miR-503, or both, increased cellular invasion and reduced noticeably the inhibitory effect of T3. Therefore, induction of these miRNAs by T3 also appears to play a role on the antiinvasive actions of the hormone (Figure 6B).

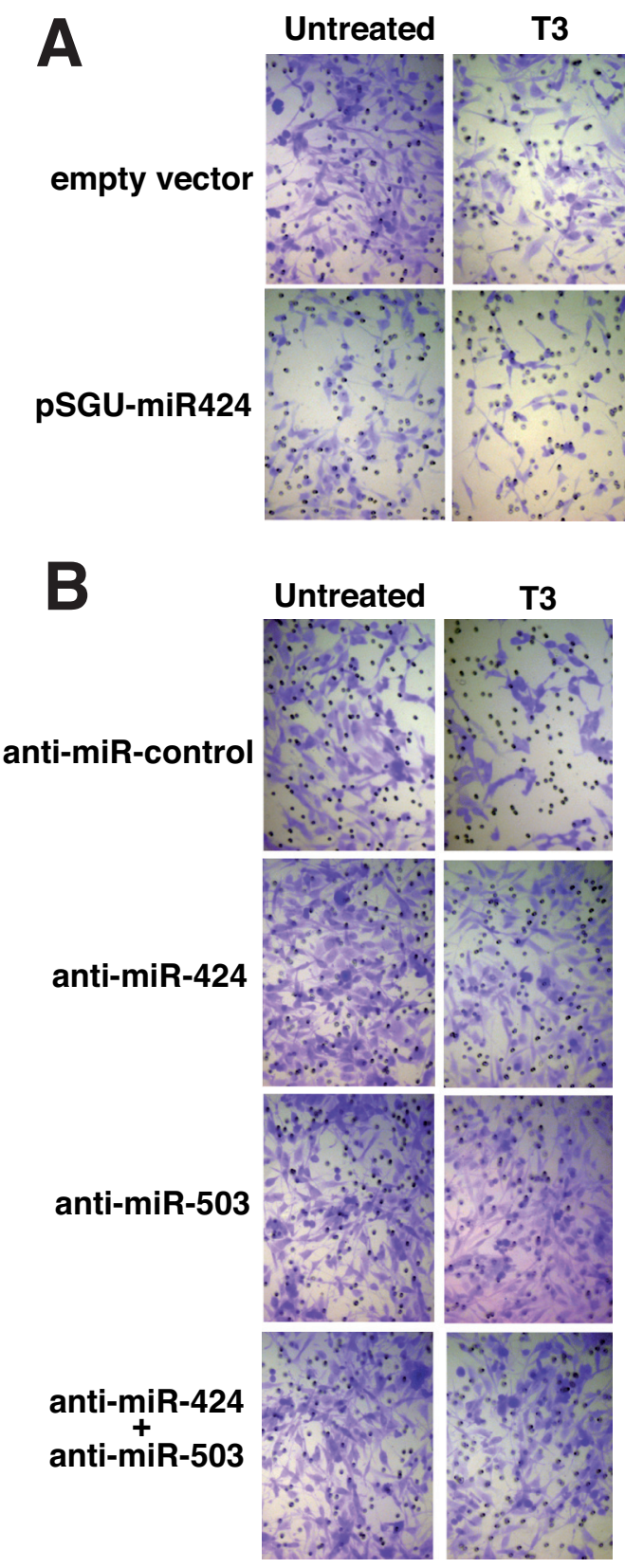

miR424/503 depletion increases extravasation of hepatocarcinoma cells

$\mathrm{TRb}$ can limit cancer cell extravasation in vivo [17]. Therefore we next determined if miR-424 and miR-503 could also regulate this process. To analyze this, SK- TRb cells transfected with a negative control of with anti-miRs were injected into the tail of nude mice. As illustrated in Figure 7, miRNA depletion increased very significantly the amount of cells present in the lungs of the mice. Therefore,
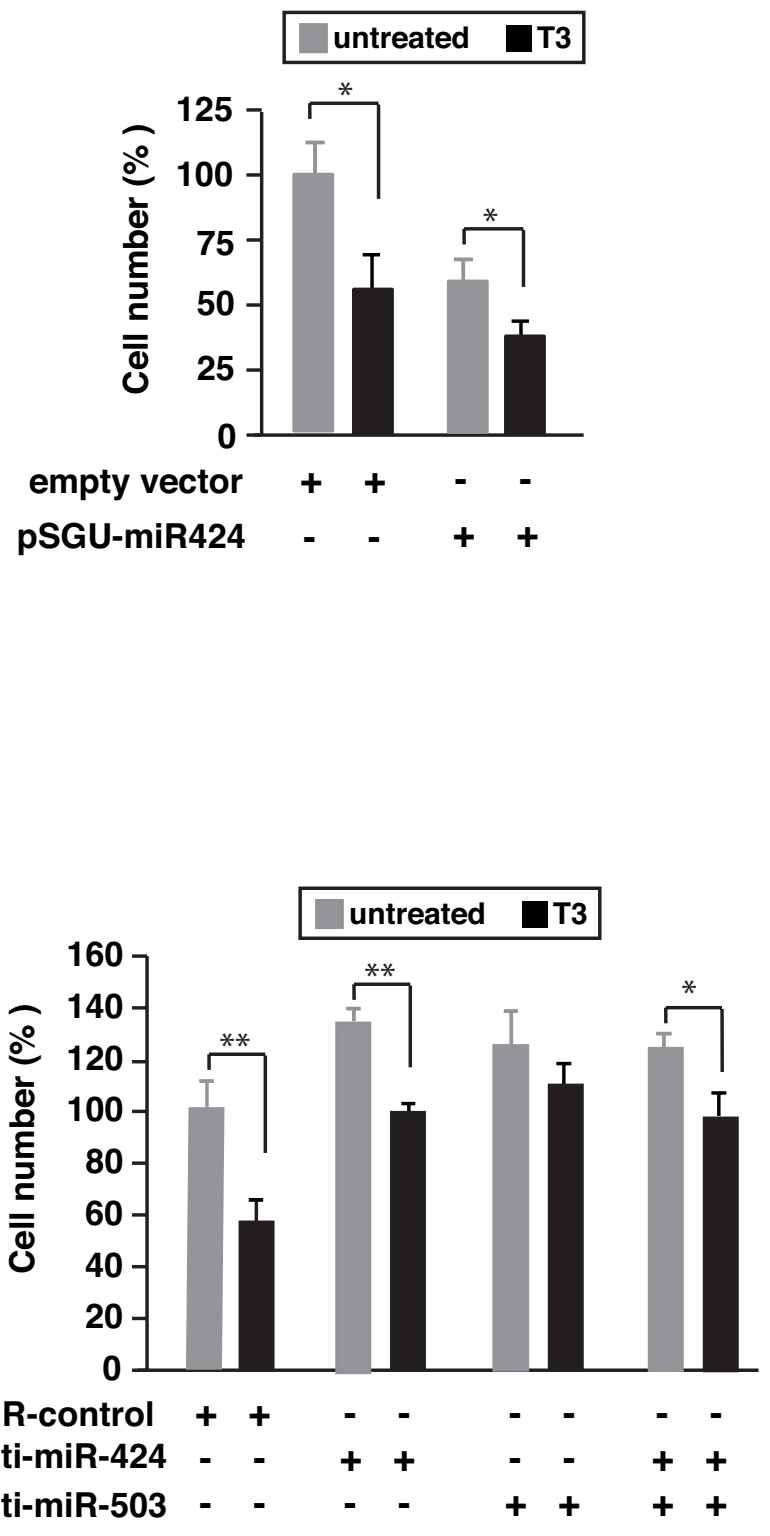

Figure 6: Depletion of miR-424 and miR-503 reduces the inhibitory effect of T3 on cellular invasion. (A) SK-TRb cells were transfected with pSGU-miR424 or the empty vector and incubated for $48 \mathrm{~h}$ in the presence and absence of T3. Cells were then inoculated into the upper chamber of Transwell plates containing matrigel and treated with or without T3. Sixteen hours later cells that passed through the filter were stained and scored. Representative images are shown at the left and quantifications at the right panel (B) Similar experiment in cells transfected with a negative control anti-miRNA, anti-miR-424, anti-miR-503 or both. 


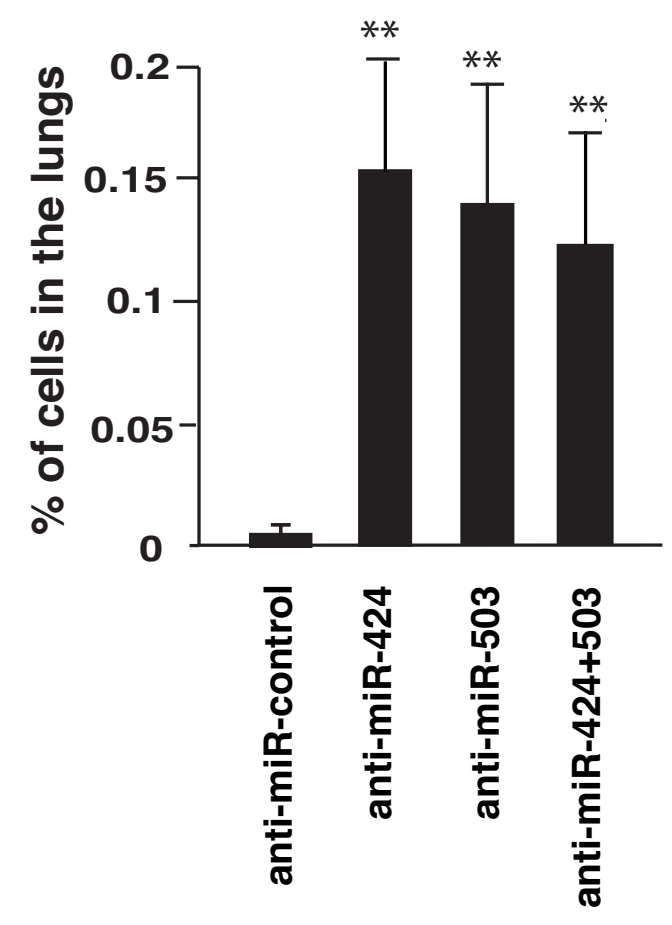

Figure 7: Depletion of miRNAs 424 and 503 enhances extravasation in vivo. SK-TRb cells transfected with a negative control or with the indicated anti-miRNAs were injected into the tail vein of nude mice. The presence of human Alu sequences in the lungs was determined by quantitative PCR at $9 \mathrm{~h}$ after injection. Data are expressed as the percentage of the inoculated DNA with respect to the total DNA injected.

the induction of miRNAs 424 and 503 by endogenous thyroid hormones could inhibit cell extravasation in vivo.

\section{T3 increases miR424 and 503 levels in breast cancer cells}

To analyze if induction of the miRNAs by T3 could also occur in other types of tumor cells, we measured the levels of miRNAs 424 and 503 in TRb-expressing MDAMB-468 breast cancer cells (MDA-TRb) cells (Figure 8A). T3 increased the levels of both miRNAs (Figure 8B), and in agreement with this induction reduced the levels of their putative target proteins (Figure 8C). The functional role of miR-424 and miR-503 induction by T3 in MDA-TRb cells was also examined. Growth in suspension was abolished by $\mathrm{T} 3$ and was restored after depletion of miR-424, miR503, or both (Figure 8D). The hormone also decreased MDA-TRb cells invasion through matrigel and expression of miR-424 had a similar effect (Figure 8E). In addition, miR-424 and/or miR-503 depletion increased cellular invasion and reduced the inhibition by T3 (Figure 8F). Therefore, induction of miRNAs 424 and 503 by T3 is also functionally relevant in breast cancer cells.

\section{Hypothyroidism reduces miR-424 and miR-503 levels in xenografts}

We have previously shown that when SK-TRb or MDA-TRb cells were inoculated into hypothyroid nude mice, tumors were more invasive and metastatic growth was enhanced [16]. To analyze whether thyroidal status could also alter miRNA expression in the tumors, we next compared miR-424 and miR-503 levels in xenografts formed by inoculation of SK-TRb and MDA-TRb cells into euthyroid and hypothyroid mice. As shown in Figure 9, miR-424 and miR-503 expression was reduced in the tumors developed in hypothyroid mice, correlating with their increased invasive properties. Thus, the thyroid hormones can regulate expression of these miRNAs in vivo in hepatocarcinoma and breast cancer cells.

\section{DISCUSSION}

In the present study, we have investigated the function of miR-424 and miR-503 in the response of hepatocarcinoma to T3. The hormone increased the levels of these miRNAs in SK-TRb cells and this induction plays an important role in the anti-tumorigenic and antiinvasive actions mediated by binding of $\mathrm{T} 3$ to the receptor. Induction of these miRNAs by T3 was also found in nontransformed hepatocytes and in MDA- TRb breast cancer cells, indicating that the phenomenon is not specific for the hepatocarcinoma cell line.

T3 increased the level of both pri-miRNAs and stimulated the activity of the proximal promoter of miR424/miR-503 in SK-TRb cells, indicating that the hormone induces transcription of the polycistronic message that 
A

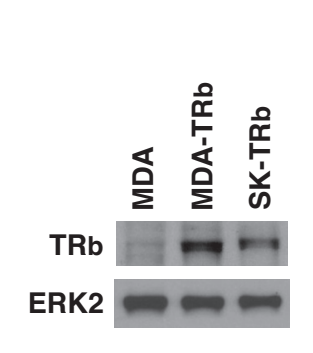

B
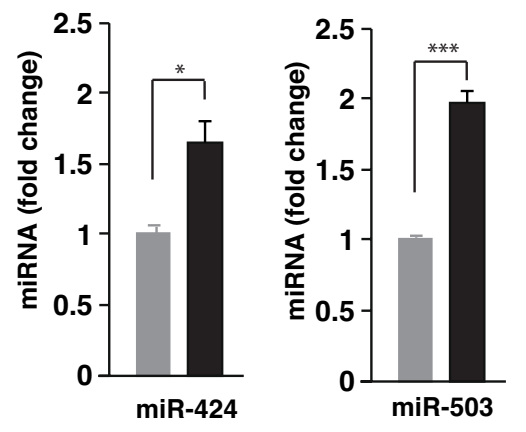

C
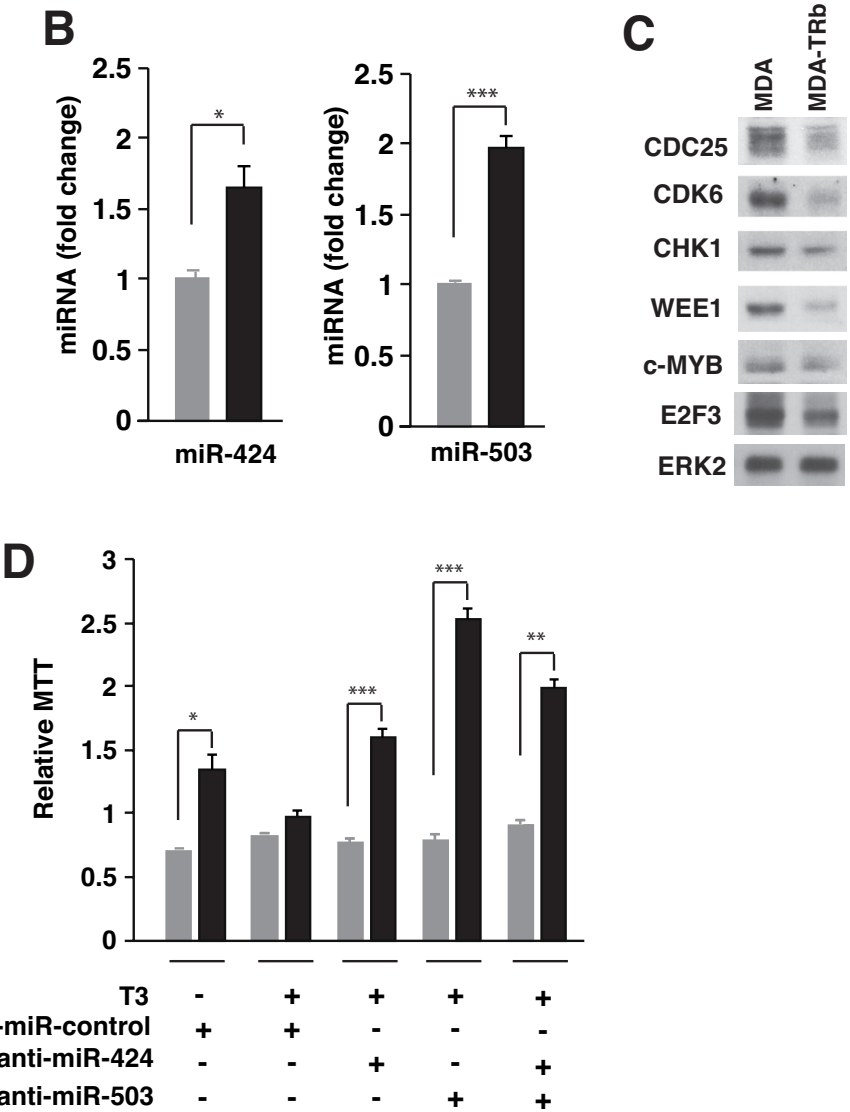
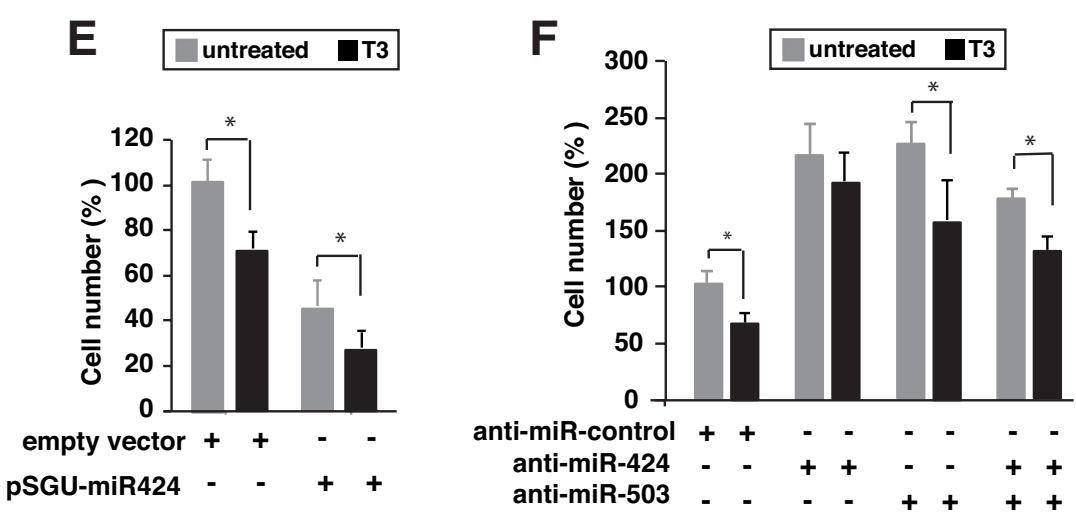

Figure 8: T3 induces expression of miR424 and miR503 in breast cancer cells. (A) Western blot analysis of TRb in parental MDA-MB-468 (MDA), TRb-expressing MDA (MDA-TRb) cells and SK-TRb cells. ERK2 was used as a loading control. (B) miR-424 and -503 levels in MDA-TRb cells after $48 \mathrm{~h}$ of treatment with 5nM T3. Fold change of these microRNAs are expressed relative to control untreated cells. (C) Western blot analysis of the putative miR424/503 targets CDC25, CDK6, CHK1, WEE1, c-MYB, and E2F3 in untreated and T3-treated MDA-TRb cells. ERK2 was used as a loading control. (D) Growth in suspension under rocking conditions was analyzed in MDA-TRb cells previously transfected with the indicated anti-miRNAs. MTT was assayed after $24 \mathrm{~h}$ growth in the presence and absence of T3. Results were expressed relative to MTT values obtained in cells inoculated in parallel without agitation. (E) Invasion through matrigel was measured in MDA-TRb cells previously transfected with pSGU-miR424 or the empty vector and incubated for $48 \mathrm{~h}$ with and without T3. Invasion was then performed for $16 \mathrm{~h}$ in the presence and absence of the hormone and the cells that passed through the filter were counted (F) Similar experiment in cells transfected with a negative control anti-miRNA, anti-miR-424, anti-miR-503 or both. The results are expressed relative to the number of cells obtained in the control untreated cells.

encodes both miRNAs. T3-dependent transcriptional stimulation of target genes involves binding of the TR to TREs, inducing the release of corepressors and the recruitment of co-activators that lead to local alteration of chromatin structure [1]. ChIP analysis confirmed that TRb binds to the miR-424/503 promoter, and that $\mathrm{T} 3$ releases the corepressor NCoR and recruits p160 coactivators such as $\mathrm{SRC}-1$ or $\mathrm{p} / \mathrm{CIP}$ with histone acetyltransferase (HAT) 
A
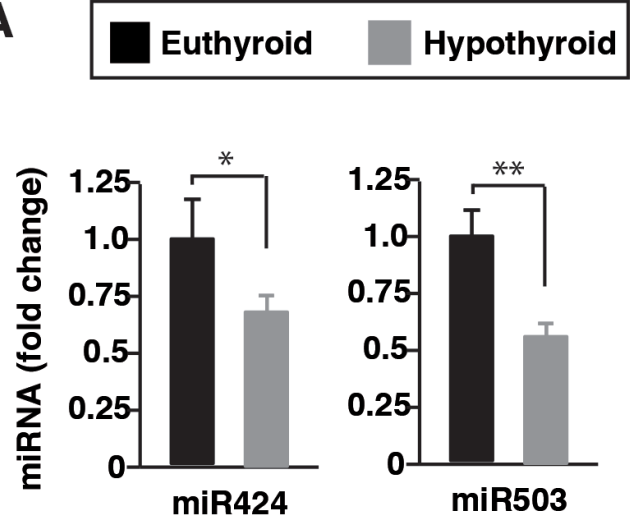

Euthyroid
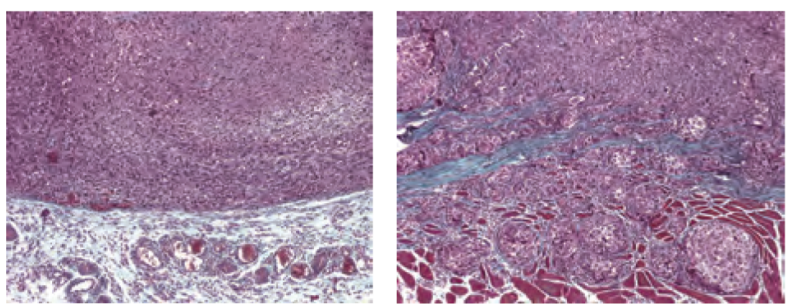

B

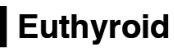

Hypothyroid

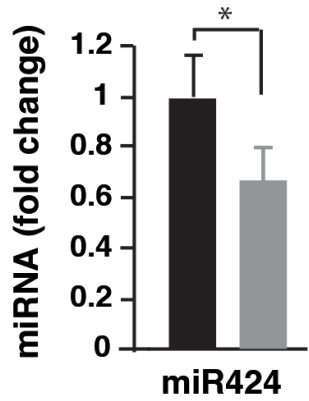

Euthyroid

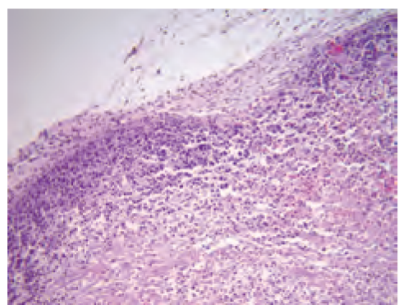

Figure 9: Reduced miR-424 and miR-503 expression in tumor xenografts developed in hypothyroid mice. Euthyroid and hypothyroid nude mice were injected with SK-TRb (A) and MDA-TRb cells (B), and the levels of miR-424 and miR-503 were determined 8 weeks later in the tumors. Representative Masson's trichrome staining of tumors formed in euthyroid and hypothyroid mice are illustrated in the bottom panels.

activity. p160 coactivators act as primary coactivators interacting with TRs, but they also recruit secondary coactivators such as the HAT CBP/p300 [43]. We observed hormone-dependent recruitment of CBP to the miR-424/503 promoter. Histone acetylation is a critical step in nuclear receptor-mediated hormone signaling and histone acetylation of the miR-424/503 promoter was also induced upon $\mathrm{T} 3$ treatment.

miR-424 and 503 play an important role in tumorigenesis. They are down-regulated in several tumors, suggesting that these miRNAs have tumor suppressive activity $[37,39,42,44,45]$, although miR-424 is upregulated in some tumors [46]. The anti-tumorigenic actions of miR-424 and miR-503 could be related to their effect on the cell cycle. Indeed, elevated levels of both promote cell quiescence and differentiation, which is consistent with the role of this family in targeting multiple genes involved in the G1-S transition [27-29, 33, 41]. Our results show that $\mathrm{T} 3$ reduces expression of several cell cycle genes in hepatocarcinoma cells including Ccnd2, Cdk6 and Cdc25 that control entry into and progression through various phases of the cell cycle; the Weel kinase, a key regulator during $\mathrm{S}$ phase, preventing entry into mitosis until DNA replication has been completed [47]; the checkpoint gene Chk1 [48]; the transcription factor E2f3, a member of the E2f family that regulates expression of genes required for DNA synthesis at the G1/S phase boundary [49]; or the c-Myb proto-oncogene also involved in cell proliferation and cancer [50]. Interestingly, expression of the target proteins of miR-424 and miR-503 was also decreased in T3-treated breast cancer cells.

The increased transcription of miR-424 and miR503 is relevant for the regulation of most of these proteins by the hormone. On one hand, T3 suppressed stability of target mRNAs in experiments with the 3 '-UTRs, which contain binding sites for miR-424/503, and on the other hand, gain- and loss-of-function experiments revealed that these miRNAs mediate T3-dependent changes in the levels of the target proteins. Furthermore, T3 arrested hepatocarcinoma cells in G1 and the knockdown of miR424 and miR-503 reversed this effect, underscoring the important role of these miRNAs in the inhibition of cell proliferation.

A decrease in the expression of the miR-16 family mediates resistance to cisplatin in cancer cells as a consequence of the increased levels of Wee1 and Chk1 [36]. Our results indicate that $\mathrm{T} 3$ significantly repressed Wee1 and Chk1 3'-UTR activity and reduced the levels of these proteins. This led us to the hypothesis that elevated expression of miR-424 and 503 in response to T3 could sensitize cancer cells to chemotherapy. In agreement with this idea, we found that hepatocarcinoma cell survival in response to cisplatin was moderately reduced after T3 treatment, suggesting a novel anti-tumorigenic mechanism 
for this hormone. Down-regulation of Chk1 could also play a role in the anti-tumorigenic effects of $\mathrm{TRb}$, since suppressed miR-424 expression via up-regulation of Chk1 contributes to the progression of cervical cancer [37].

Our results show that miR-424 and 503 affected hepatocarcinoma and breast cancer cell invasion in vitro. This is consistent with the previous report that miR-503 was down-regulated in the highly metastatic hepatocarcinoma cell line HCCLM3 when compared with MHCC97-L cells with a lower metastatic potential [39]. The invasive capacity of T3-treated cells was significantly recovered after depletion of miR-424 and 503, indicating that induction of these miRNAs participates in T3dependent inhibition of SK-TRb and MDA-TRb cell invasion.

The in vivo relevance of thyroid hormone regulation of miR-424 and 503 was demonstrated by the finding that tumor xenografts formed by SK-TRb and MDA$\mathrm{TRb}$ cells in hypothyroid mice expressed lower levels of these miRNAs than those developed in animals with normal thyroid function. Interestingly, correlating with the lower levels of miR-424 and 503 the tumors formed in the hypothyroid hosts had a more mesenchymal phenotype and were more invasive [17].

TRb-expressing hepatocarcinoma cells have a reduced capacity of extravasation to the lungs when they are injected into the tail vein of nude mice. Therefore, the receptor appears to have anti-metastatic activity by blocking not only the ability of cancer cells to proliferate and colonize the lung parenchyma, but also by limiting cancer cell extravasation [17]. Here we show that extravasation of hepatocarcinoma cells in vivo was strongly enhanced when miRNAs 424 and 503 were depleted. Therefore, induction of these miRNAs could play an important role in the inhibitory action of the receptor. Additionally, miR-424 and miR-503 depletion restored the ability of T3-treated hepatocarcinoma and breast cancer cells to growth in suspension under rocking conditions. The competence to grow under these circumstances should enhance survival of cells in the circulation and therefore increase their ability to metastatize.

Taken together our results show that binding of $\mathrm{T} 3$ to the $\mathrm{TRb}$ receptor induces transcription of miR424 and miR-503. This induction is relevant to explain the tumor suppressive actions of this nuclear receptor. The thyroid hormone-dependent increase of miR-424 and miR-503 appears to modulate tumor growth and progression in multiple ways. Besides affecting tumor cell proliferation and increasing sensitivity to DNA damaging agents, elevated levels of miR-424 and miR-503 are required for the inhibitory effect of the hormone on cell migration and invasion. As suggested by our results, the increased miRNA expression could reduce tumor invasion, intravasation, survival of the cancer cells in the bloodstream, and the extravasation and colonization of the metastatized target tissue. There are many predicted targets of miR-424/503 and future studies are necessary to identify the genes responsible for the inhibition of cell migration and invasion by these miRNAs that could affect tumor progression in vivo.

In summary, our findings suggest that increased transcription of miRNAs 424 and 503 secondary to thyroid hormone binding to its receptor plays a relevant role in the anti-proliferative and anti-invasive actions of this nuclear receptor in tumor cells. These miRNAs appear to have tumor suppressive actions and could be potential therapeutic targets.

\section{MATERIALS AND METHODS}

\section{Cells}

Human hepatocarcinoma SK-TRb cells and MDA$\mathrm{TRb}$ cells, stably expressing the beta 1 isoform of the thyroid hormone receptor were derived from SK-hep1 and MDA-MB-468 cells, respectively, as previously described [17]. Hep-G2 cells expressing TRb were a kind gift of M. Privalsky. Parental and TRb cells were maintained in Dulbecco's modified Eagle's media (DMEM) supplemented with 10\% fetal bovine serum (FBS) depleted of thyroid hormones by treatment with resin AG-1-X8 (Bio-Rad). The human hepatocyte cell line HH4, a gift of J. Campbell and I. Fabregat, was cultured in collagen-coated plates with William's E medium containing $15 \%$ fetal calf serum. The cell line THLE-2 derived from primary normal liver cells, a gift of P. Martín, was cultured in Airway Epithelial cell Media (PromoCell ref-21160). When indicated, cells were incubated in serum free medium.

\section{Retroviral infection}

HEK293T cells were cotransfected with $10 \mu \mathrm{g}$ of pLPCX or pLPCX-TRb that encodes the human TRb isoform, $3.5 \mu \mathrm{g}$ of VSV, and $6.5 \mu \mathrm{g}$ of gag-pol constructs (a gift from Dr. P.M. Comoglio) using calcium phosphate. Viral supernatants were harvested 24 and $48 \mathrm{~h}$ posttransfection, filtered, and used for infections of $\mathrm{HH} 4$ cells in the presence of $4 \mu \mathrm{g} / \mathrm{ml}$ of polybrene. Cells were selected with $2 \mu \mathrm{g} / \mathrm{ml}$ puromycin. Pools of resistant cells (HH4-TRb cells) were cultured with thyroid hormonedepleted FBS.

\section{Plasmids}

Fragments $+28953 /+29193$ and $+13948 /+14644$ of the 3'-UTR of the CHEK1 and WEE1 mRNAs with predicted miR-424/503 target binding sequences were amplified by PCR using the primers listed under Supplementary material. These fragments were cloned downstream of the luciferase coding region in pGL3 vector. Reporter plasmids containing the wild-type and 
mutant 3'-UTRs of Cdc25 and c-Myb were a king gift of A. Dutta and F. Grässer and were described previously $[41,42]$. The expression vector for miR-424 (pSGUmiR424) and the corresponding empty vector were a kind gift from I.V. Ramakrishnan [34]. Fragments of the 5 '-flanking region of miR424/503 were obtained by PCR and were cloned in pGL3 with the primers listed under Supplementary materials.

\section{Transfection and reporter assays}

Cells, grown in 24 wells plates, were transiently transfected with $300 \mathrm{ng}$ of reporter plasmids and $30 \mathrm{ng}$ of pRL-TK-Renilla (Promega) as a normalizer control, using TransFectin ${ }^{\mathrm{TM}}$ (BioRad). When appropriate, the reporter was cotransfected with an expression vector for miR-424 (pSGU-miR424, $200 \mathrm{ng}$ ) or with the same amount of an empty vector. Anti-miR Inhibitor for miR424, miR-503 and the Anti-miR Negative Control\#1 were purchased from Ambion (Cat. AM10306 and AM10378). Transfection of miRNA inhibitors was performed using $60 \mathrm{nM}$ of each Anti-miR and TransFectin ${ }^{\mathrm{TM}}$ (BioRad) as recommended by the manufacturer. Each experiment was performed in triplicate and was repeated at least 3 times. Data are mean \pm S.D and are expressed as fold induction over the values obtained in the control cells.

\section{Quantitative real time RT-PCR analysis of miRNAs, pri-miRNAs and mRNAs}

miR-424 and miR-503 were quantified by the stemloop real-time PCR, with primers purchased from Applied Biosystems. RNU48 RNA was used as an internal control. Pri-miRNA levels were analyzed by quantitative real-time PCR using specific primers from TaqMan Pri-miRNA Assays (Applied Biosystems). PCRs reactions were detected with FastStartUniversal Sybr Green (Roche). Data analysis was done using the comparative CT method and data were corrected with the RPL19 mRNA levels. Primers used are indicated in the Supplementary material.

\section{Western blotting}

Proteins from cell lysates $(20-40 \mu \mathrm{g})$ were separated in SDS-PAGE and transferred to PDVF membranes (Immobilon Millipore) that were blocked with 4\% BSA. Incubation with primary antibodies was performed overnight at $4^{\circ} \mathrm{C}$ and with the secondary antibody for $1 \mathrm{~h}$ at room temperature. Primary antibodies and the dilution used are listed in the Supplementary material.

\section{Chromatin immunoprecipitation assays}

Cells were plated in $150 \mathrm{~mm}$ dishes and treated with $5 \mathrm{nM}$ T3 for $1 \mathrm{~h}$, fixed, lysed following specifications of 17 295 Upstate kit, and sonicated in a Bioruptor UCD-200TM (Diagenode, Belgium). In each immunoprecipitation $4 \times 10^{6}$ cells and the antibodies listed in the Supplementary material were used. DNA was purified, precipitated and the fragments of miR424/503 promoter amplified with the primers listed under Supplementary material.

\section{Growth in suspension}

Cells were inoculated in the presence or absence of $5 \mathrm{nM}$ T3 and kept under agitation under rocking conditions for $24 \mathrm{~h}$. Cells were then plated in 24-wells plates and after $4 \mathrm{~h}$ were used for MTT assays. Results were expressed relative to MTT values obtained in cells inoculated in parallel without agitation.

\section{Flow Cytometry}

Floating and adherent cells from triplicate cultures were collected, washed, fixed and centrifuged. Pellets were stained with propidium iodide and sorted in FACScan Q4 (Becton Dickinson, Mountain View, CA) cell sorter. Percentages of cells in sub-G1, G1, S, and G2-M phases were calculated with Mod Fit software for Windows.

\section{Migration assays}

For migration assays, cells were plated in wells containing Culture-Inserts (Ibidi). Twenty-four hours later cells were treated for $2 \mathrm{~h}$ with $10 \mu \mathrm{g} / \mathrm{ml}$ mitomycin $\mathrm{C}$ and inserts were removed. Wound healing was followed for 3 days and photographs were taken at the beginning of the assay $(t=0 \mathrm{~h})$ and at day 3 at magnification $\times 100$.

\section{Invasion assays}

Cells were inoculated in Transwell plates containing matrigel. Conditioned medium obtained from NIH3T3 cells incubated for $48 \mathrm{~h}$ in serum-free-medium and $0.1 \%$ bovine serum abumin (BSA) was placed in the outer chamber. Medium containing $0.1 \%$ BSA was used as a negative control. Invasion lasted for $16 \mathrm{~h}$, and occurred in the presence and absence of hormone. Filters were fixed with methanol and cells were stained with crystal violet, sealed with Mowiol and scored.

\section{Xenografts}

Groups of athymic nude mice (athymic nude- $\mathrm{Nu}$ ) 8-10 weeks old were used for xenografting studies. SK-TRb cells $\left(1 \times 10^{6}\right.$ cells in $\left.100 \mu \mathrm{PBS}\right)$ were injected subcutaneously into each flank, and MDA-TRb cells were orthotopically inoculated into the fat pad of the second abdominal right mammary gland. Cells were implanted in euthyroid mice and in mice made hypothyroid by treatment with $0.02 \%$ methymazole and $0.1 \%$ potassium perchlorate in the drinking water as described previously [16]. Experiments were carried out following the regulations of the CSIC for animal care and handling (RD 53/2013). Tumors were fixed in $4 \%$ buffered formalin and embedded in paraffin wax, and sections $(4-5 \mu \mathrm{m})$ were stained with 
Masson's Trichrome. miR-424 and miR-503 levels were analyzed in the tumors 8 weeks after inoculation.

\section{Extravasation assays in nude mice}

Groups of 6 immunodeficient nude mice were injected into the tail vein with $4 \times 10^{6} \mathrm{SK}-\mathrm{TRb}$ cells suspended in $100 \mu \mathrm{l}$ of PBS. Animals were sacrificed and exsanguinated by intra-cardiac puncture at $9 \mathrm{~h}$ after injection. Lungs were excised and placed in vials containing 1 xPBS. PBS was changed daily for 3 days to eliminate non-incorporated cells. Lungs were divided into 3 pieces (upper, medium and lower) and genomic DNA was extracted from the different segments. Colonization of the organ by the hepatocarcinoma cells was quantitated by real-time PCR of human APO Alu sequences located in human chromosome 11 [51], with the primers listed in the Supplementary material. Results are expressed as the $\%$ of amplified human DNA, with respect to the amount of total DNA injected. No amplification of human Alu sequences was found in blood, which was used as a negative control.

\section{Statistical analysis}

Data are expressed as means \pm S.D. Statistical significance was determined by Student t-test or analysis of variance (ANOVA) followed by the Bonferroni test for experiments with more than two experimental groups. Significance between untreated and T3-treated cells is indicated in the figures as $* \mathrm{P}<0.05, * * \mathrm{P}<0.01$ and $* * * \mathrm{P}<0.001$. All analysis were performed using SPSS (Statistical Software for Social Sciences, Chicago, IL, USA).

\section{ACKNOWLEDGEMENTS}

We thank A Dutta, F Grässer, S Ramakrishnan and PM Comoglio for plasmids, M. Privasky, P. Martín, J. Campbell and I. Fabregat for cells and M SánchezPrieto for technical help. This work was supported by Grants from Ministerio de Economía y Competitividad BFU2011-28058, from the Instituto de Salud Carlos III RD12/0036/0030, and from the Comunidad de Madrid S2011/BMD-2328 (TIRONET).

\section{CONFLICT OF INTEREST}

The authors declare that they have no conflict of interest.

\section{REFERENCES}

1. Aranda A and Pascual A. Nuclear hormone receptors and gene expression. Physiological reviews. 2001; 81(3): 1269-1304.
2. Aranda A, Martinez-Iglesias O, Ruiz-Llorente L, GarciaCarpizo V and Zambrano A. Thyroid receptor: roles in cancer. Trends Endocrinol Metab. 2009; 20(7):318-324.

3. Pascual A and Aranda A. Thyroid hormone receptors, cell growth and differentiation. Biochimica et biophysica acta. 2013; 1830(7):3908-3916.

4. Yen CC, Huang YH, Liao CY, Liao CJ, Cheng WL, Chen WJ and Lin KH. Mediation of the inhibitory effect of thyroid hormone on proliferation of hepatoma cells by transforming growth factor-beta. J Mol Endocrinol. 2006; 36(1):9-21.

5. Garcia-Silva S, Martinez-Iglesias O, Ruiz-Llorente L and Aranda A. Thyroid hormone receptor betal domains responsible for the antagonism with the ras oncogene: role of corepressors. Oncogene. 2011; 30(7):854-864.

6. Chen RN, Huang YH, Yeh CT, Liao $\mathrm{CH}$ and Lin $\mathrm{KH}$. Thyroid hormone receptors suppress pituitary tumor transforming gene 1 activity in hepatoma. Cancer research. 2008; 68(6):1697-1706.

7. Ledda-Columbano GM, Perra A, Loi R, Shinozuka H and Columbano A. Cell proliferation induced by triiodothyronine in rat liver is associated with nodule regression and reduction of hepatocellular carcinomas. Cancer research. 2000; 60(3):603-609.

8. Perra A, Kowalik MA, Pibiri M, Ledda-Columbano GM and Columbano A. Thyroid hormone receptor ligands induce regression of rat preneoplastic liver lesions causing their reversion to a differentiated phenotype. Hepatology. 2009; 49(4):1287-1296.

9. Chan IH and Privalsky ML. Thyroid hormone receptors mutated in liver cancer function as distorted antimorphs. Oncogene. 2006; 25(25):3576-3588.

10. Chan IH and Privalsky ML. Thyroid hormone receptor mutants implicated in human hepatocellular carcinoma display an altered target gene repertoire. Oncogene. 2009; 28(47):4162-4174.

11. Lin $\mathrm{KH}, \mathrm{Wu} \mathrm{YH}$ and Chen SL. Impaired interaction of mutant thyroid hormone receptors associated with human hepatocellular carcinoma with transcriptional coregulators. Endocrinology. 2001; 142(2):653-662.

12. Lin KH, Zhu XG, Hsu HC, Chen SL, Shieh HY, Chen ST, McPhie P and Cheng SY. Dominant negative activity of mutant thyroid hormone alphal receptors from patients with hepatocellular carcinoma. Endocrinology. 1997; 138(12):5308-5315.

13. Conde I, Paniagua R, Zamora J, Blanquez MJ, Fraile B, Ruiz A and Arenas MI. Influence of thyroid hormone receptors on breast cancer cell proliferation. Ann Oncol. 2006; 17(1):60-64.

14. Li Z, Meng ZH, Chandrasekaran R, Kuo WL, Collins CC, Gray JW and Dairkee SH. Biallelic inactivation of the thyroid hormone receptor betal gene in early stage breast cancer. Cancer research. 2002; 62(7):1939-1943. 
15. Silva JM, Dominguez G, Gonzalez-Sancho JM, Garcia JM, Silva J, Garcia-Andrade C, Navarro A, Munoz A and Bonilla F. Expression of thyroid hormone receptor/erbA genes is altered in human breast cancer. Oncogene. 2002; 21(27):4307-4316.

16. Martinez-Iglesias O, Garcia-Silva S, Regadera J and Aranda A. Hypothyroidism enhances tumor invasiveness and metastasis development. PLoS One. 2009; 4(7):e6428.

17. Martinez-Iglesias O, Garcia-Silva S, Tenbaum SP, Regadera J, Larcher F, Paramio JM, Vennstrom B and Aranda A. Thyroid hormone receptor betal acts as a potent suppressor of tumor invasiveness and metastasis. Cancer research. 2009; 69(2):501-509.

18. Sayed D and Abdellatif M. MicroRNAs in development and disease. Physiological reviews. 2011; 91(3):827-887.

19. Bartel DP. MicroRNAs: target recognition and regulatory functions. Cell. 2009; 136(2):215-233.

20. Guo H, Ingolia NT, Weissman JS and Bartel DP. Mammalian microRNAs predominantly act to decrease target mRNA levels. Nature. 2010; 466(7308):835-840.

21. Baek D, Villen J, Shin C, Camargo FD, Gygi SP and Bartel DP. The impact of microRNAs on protein output. Nature. 2008; 455(7209):64-71.

22. Fabian MR and Sonenberg N. The mechanics of miRNAmediated gene silencing: a look under the hood of miRISC. Nature structural \& molecular biology. 2012; 19(6):586-593.

23. Esquela-Kerscher A and Slack FJ. Oncomirs - microRNAs with a role in cancer. Nature reviews Cancer. 2006; 6(4):259-269.

24. Garzon R and Marcucci G. Potential of microRNAs for cancer diagnostics, prognostication and therapy. Current opinion in oncology. 2012; 24(6):655-659.

25. Kong YW, Ferland-McCollough D, Jackson TJ and Bushell M. microRNAs in cancer management. The lancet oncology. 2012; 13(6):e249-258.

26. Finnerty JR, Wang WX, Hebert SS, Wilfred BR, Mao G and Nelson PT. The miR-15/107 group of microRNA genes: evolutionary biology, cellular functions, and roles in human diseases. Journal of molecular biology. 2010; 402(3):491-509.

27. Linsley PS, Schelter J, Burchard J, Kibukawa M, Martin MM, Bartz SR, Johnson JM, Cummins JM, Raymond CK, Dai H, Chau N, Cleary M, Jackson AL, Carleton M and Lim L. Transcripts targeted by the microRNA-16 family cooperatively regulate cell cycle progression. Molecular and cellular biology. 2007; 27(6):2240-2252.

28. Liu Q, Fu H, Sun F, Zhang H, Tie Y, Zhu J, Xing R, Sun Z and Zheng $\mathrm{X}$. miR-16 family induces cell cycle arrest by regulating multiple cell cycle genes. Nucleic acids research. 2008; 36(16):5391-5404.

29. Rissland OS, Hong SJ and Bartel DP. MicroRNA destabilization enables dynamic regulation of the miR-16 family in response to cell-cycle changes. Molecular cell. 2011; 43(6):993-1004.
30. Griffiths-Jones S, Saini HK, van Dongen S and Enright AJ. miRBase: tools for microRNA genomics. Nucleic acids research. 2008; 36(Database issue):D154-158.

31. Caporali A and Emanueli C. MicroRNA-503 and the extended microRNA-16 family in angiogenesis. Trends in cardiovascular medicine. 2011; 21(6):162-166.

32. Chamorro-Jorganes A, Araldi E, Penalva LO, Sandhu D, Fernandez-Hernando $\mathrm{C}$ and Suarez Y. MicroRNA-16 and microRNA-424 regulate cell-autonomous angiogenic functions in endothelial cells via targeting vascular endothelial growth factor receptor-2 and fibroblast growth factor receptor-1. Arteriosclerosis, thrombosis, and vascular biology. 2011; 31(11):2595-2606.

33. Forrest AR, Kanamori-Katayama M, Tomaru Y, Lassmann T, Ninomiya N, Takahashi Y, de Hoon MJ, Kubosaki A, Kaiho A, Suzuki M, Yasuda J, Kawai J, Hayashizaki Y, Hume DA and Suzuki H. Induction of microRNAs, mir-155, mir-222, mir-424 and mir-503, promotes monocytic differentiation through combinatorial regulation. Leukemia. 2010; 24(2):460-466.

34. Ghosh G, Subramanian IV, Adhikari N, Zhang X, Joshi HP, Basi D, Chandrashekhar YS, Hall JL, Roy S, Zeng Y and Ramakrishnan S. Hypoxia-induced microRNA-424 expression in human endothelial cells regulates HIF-alpha isoforms and promotes angiogenesis. The Journal of clinical investigation. 2010; 120(11):4141-4154.

35. Nakashima T, Jinnin M, Etoh T, Fukushima S, Masuguchi S, Maruo K, Inoue Y, Ishihara T and Ihn H. Down-regulation of mir-424 contributes to the abnormal angiogenesis via MEK1 and cyclin E1 in senile hemangioma: its implications to therapy. PLoS One. 2010; 5(12):e14334.

36. Pouliot LM, Chen YC, Bai J, Guha R, Martin SE, Gottesman MM and Hall MD. Cisplatin sensitivity mediated by WEE1 and CHK1 is mediated by miR-155 and the miR-15 family. Cancer research. 2012; 72(22):5945-5955.

37. Xu J, Li Y, Wang F, Wang X, Cheng B, Ye F, Xie X, Zhou C and $\mathrm{Lu}$ W. Suppressed miR-424 expression via upregulation of target gene Chk1 contributes to the progression of cervical cancer. Oncogene. 2013; 32(8):976-987.

38. Long XH, Mao JH, Peng AF, Zhou Y, Huang SH and Liu ZL. Tumor suppressive microRNA-424 inhibits osteosarcoma cell migration and invasion via targeting fatty acid synthase. Experimental and therapeutic medicine. 2013; 5(4):1048-1052.

39. Zhou J and Wang W. Analysis of microRNA expression profiling identifies microRNA-503 regulates metastatic function in hepatocellular cancer cell. Journal of surgical oncology. 2011; 104(3):278-283.

40. Zhou B, Ma R, Si W, Li S, Xu Y, Tu X and Wang Q. MicroRNA-503 targets FGF2 and VEGFA and inhibits tumor angiogenesis and growth. Cancer letters. 2013; 333(2):159-169.

41. Sarkar S, Dey BK and Dutta A. MiR-322/424 and -503 are induced during muscle differentiation and promote cell 
cycle quiescence and differentiation by down-regulation of Cdc25A. Molecular biology of the cell. 2010; 21(13): 2138-2149.

42. Imig J, Motsch N, Zhu JY, Barth S, Okoniewski M, Reineke T, Tinguely M, Faggioni A, Trivedi P, Meister G, Renner $\mathrm{C}$ and Grasser FA. microRNA profiling in EpsteinBarr virus-associated B-cell lymphoma. Nucleic acids research. 2011; 39(5):1880-1893.

43. York B and O'Malley BW. Steroid receptor coactivator (SRC) family: masters of systems biology. The Journal of biological chemistry. 2010; 285(50):38743-38750.

44. Faraoni I, Laterza S, Ardiri D, Ciardi C, Fazi F and Lo-Coco F. MiR-424 and miR-155 deregulated expression in cytogenetically normal acute myeloid leukaemia: correlation with NPM1 and FLT3 mutation status. Journal of hematology \& oncology. 2012; 5:26.

45. Pallasch CP, Patz M, Park YJ, Hagist S, Eggle D, Claus R, Debey-Pascher S, Schulz A, Frenzel LP, Claasen J, Kutsch N, Krause G, Mayr C, Rosenwald A, Plass C, Schultze JL, et al. miRNA deregulation by epigenetic silencing disrupts suppression of the oncogene PLAG1 in chronic lymphocytic leukemia. Blood. 2009; 114(15):3255-3264.
46. Wang $\mathrm{X}$, Wang $\mathrm{J}$, Ma $\mathrm{H}$, Zhang $\mathrm{J}$ and Zhou $\mathrm{X}$. Downregulation of miR-195 correlates with lymph node metastasis and poor prognosis in colorectal cancer. Med Oncol. 2012; 29(2):919-927.

47. Aarts M, Linardopoulos S and Turner NC. Tumour selective targeting of cell cycle kinases for cancer treatment. Current opinion in pharmacology. 2013.

48. Harper JW and Elledge SJ. The DNA damage response: ten years after. Molecular cell. 2007; 28(5):739-745.

49. Emmrich S and Putzer BM. Checks and balances: E2FmicroRNA crosstalk in cancer control. Cell Cycle. 2010; 9(13):2555-2567.

50. Ramsay RG and Gonda TJ. MYB function in normal and cancer cells. Nature reviews Cancer. 2008; 8(7):523-534.

51. Garcia-Obregon S, Alfonso-Sanchez MA, Perez-Miranda AM, Vidales C, Arroyo D and Pena JA. Genetic position of Valencia (Spain) in the Mediterranean basin according to Alu insertions. American journal of human biology : the official journal of the Human Biology Council. 2006; 18(2):187-195. 